\title{
An estimation method of soil wind erosion in Inner Mongolia of China based on geographic information system and remote sensing
}

\author{
Yi ZHOU ${ }^{1}$, Bing GUO ${ }^{1,2 *}$, ShiXin WANG ${ }^{1}$, HePing TAO $^{3}$ \\ ${ }^{1}$ Institute of Remote Sensing and Digital Earth, Chinese Academy of Sciences, Beijing 100094, China; \\ ${ }^{2}$ University of Chinese Academy of Sciences, Beijing 100049, China; \\ ${ }^{3}$ Institute of Mountain Hazards and Environment, Chinese Academy of Sciences, Chengdu 610041, China
}

\begin{abstract}
Studies of wind erosion based on Geographic Information System (GIS) and Remote Sensing (RS) have not attracted sufficient attention because they are limited by natural and scientific factors. Few studies have been conducted to estimate the intensity of large-scale wind erosion in Inner Mongolia, China. In the present study, a new model based on five factors including the number of snow cover days, soil erodibility, aridity, vegetation index and wind field intensity was developed to quantitatively estimate the amount of wind erosion. The results showed that wind erosion widely existed in Inner Mongolia. It covers an area of approximately $90 \times 10^{4} \mathrm{~km}^{2}$, accounting for $80 \%$ of the study region. During 1985-2011, wind erosion has aggravated over the entire region of Inner Mongolia, which was indicated by enlarged zones of erosion at severe, intensive and mild levels. In Inner Mongolia, a distinct spatial differentiation of wind erosion intensity was noted. The distribution of change intensity exhibited a downward trend that decreased from severe increase in the southwest to mild decrease in the northeast of the region. Zones occupied by barren land or sparse vegetation showed the most severe erosion, followed by land occupied by open shrubbery. Grasslands would have the most dramatic potential for changes in the future because these areas showed the largest fluctuation range of change intensity. In addition, a significantly negative relation was noted between change intensity and land slope. The relation between soil type and change intensity differed with the content of $\mathrm{CaCO}_{3}$ and the surface composition of sandy, loamy and clayey soils with particle sizes of $0-1 \mathrm{~cm}$. The results have certain significance for understanding the mechanism and change process of wind erosion that has occurred during the study period. Therefore, the present study can provide a scientific basis for the prevention and treatment of wind erosion in Inner Mongolia.
\end{abstract}

Keywords: wind erosion; estimation model; soil erodibility; snow cover days; aridity; Inner Mongolia

Citation: Yi ZHOU, Bing GUO, ShiXin WANG, HePing TAO. 2015. An estimation method of soil wind erosion in Inner Mongolia of China based on geographic information system and remote sensing. Journal of Arid Land, 7(3): 304-317. doi: 10.1007/s40333-015-0122-0

Soil wind erosion is referred to the process of denudation, selection and transportation of soil particles by wind (Singh et al., 1999; Shi et al., 2003). China is one of the countries suffering the most serious soil wind erosion in the world, with $60.9 \%$ of its territories under the influence of wind erosion (Zhu and Chen, 1994; Li et al., 2002). Soil wind erosion has caused severe land degradation and soil productivity loss, and thus has threatened the sustainable development of rural areas.

The significant adverse effects that global warming has exerted on terrestrial ecosystems during the recent past decades have been projected to be greater in the future (Fu et al., 2007; IPCC, 2007). Continuously rising temperatures and decreased precipitation have significantly exacerbated the process of wind erosion in arid and semi-arid regions, particularly in Inner Mongolia of China (Li et al., 2002; Li et al., 2004).

*Corresponding author: Bing GUO (E-mail: guobingj1@163.com) 
According to the second national soil erosion remote sensing survey, wind erosion is severe in Inner Mongolia, particularly in the midwestern region, because of drought, overgrazing of grasslands and human activities (Nakano et al., 2008). Therefore, an accurate quantitative evaluation of soil wind erosion in Inner Mongolia is urgent for ecological and environmental protection.

However, a lack of accurate information on such factors as metrological data and soil types leads to a critical limitation in the study of large-scale soil wind erosion (Jiang et al., 2003; Hevia et al., 2007). Currently, systematic research in this regard is mostly at the macro level and focuses on natural conditions of wind erosion, sandstorm activities and regular sandstorm movement (McHenry and Ritchie, 1977; Sutherland et al., 1991; Bajracharya et al., 1998; Merrill et al., 1999; Zhang et al., 2003; Buschiazzo and Zobeck, 2008). Many previous studies were based on site surveys, fixed position observations and experiments, which were conducted to simulate the process of soil wind erosion (Bilbro and Fryrear, 1994; Fryrear et al., 1994; Thorne et al., 2003; Verheijen et al., 2009).
However, little research has been conducted to investigate the estimation model of soil wind erosion on a large scale based on Geographic Information System (GIS) and Remote Sensing (RS).

The current state of the environment is critical for environmental prediction and management (Assefa, 2004). Thus, detailed information on soil wind erosion is urgent in Inner Mongolia, an important agriculturelivestock region that is ecologically vulnerable. In this paper, a new evaluation model of soil wind erosion based on GIS and RS was established to determine the state and dynamic changes of soil wind erosion for the study period of 1985-2011.

\section{Materials and methods}

\subsection{Study area}

Inner Mongolia is located in northern China, extending 2,400 km from east to west and $1,700 \mathrm{~km}$ from south to north $\left(36^{\circ}-53^{\circ} \mathrm{N}, 105^{\circ}-136^{\circ} \mathrm{E}\right.$; Li et al., 2002 ; Fig. 1). The terrain covers an area of $1.18 \times 10^{6} \mathrm{~km}^{2}$ and is approximately $1,000 \mathrm{~m}$ above sea level. The annual average temperature ranges from $-1{ }^{\circ} \mathrm{C}$ to $10^{\circ} \mathrm{C}$,

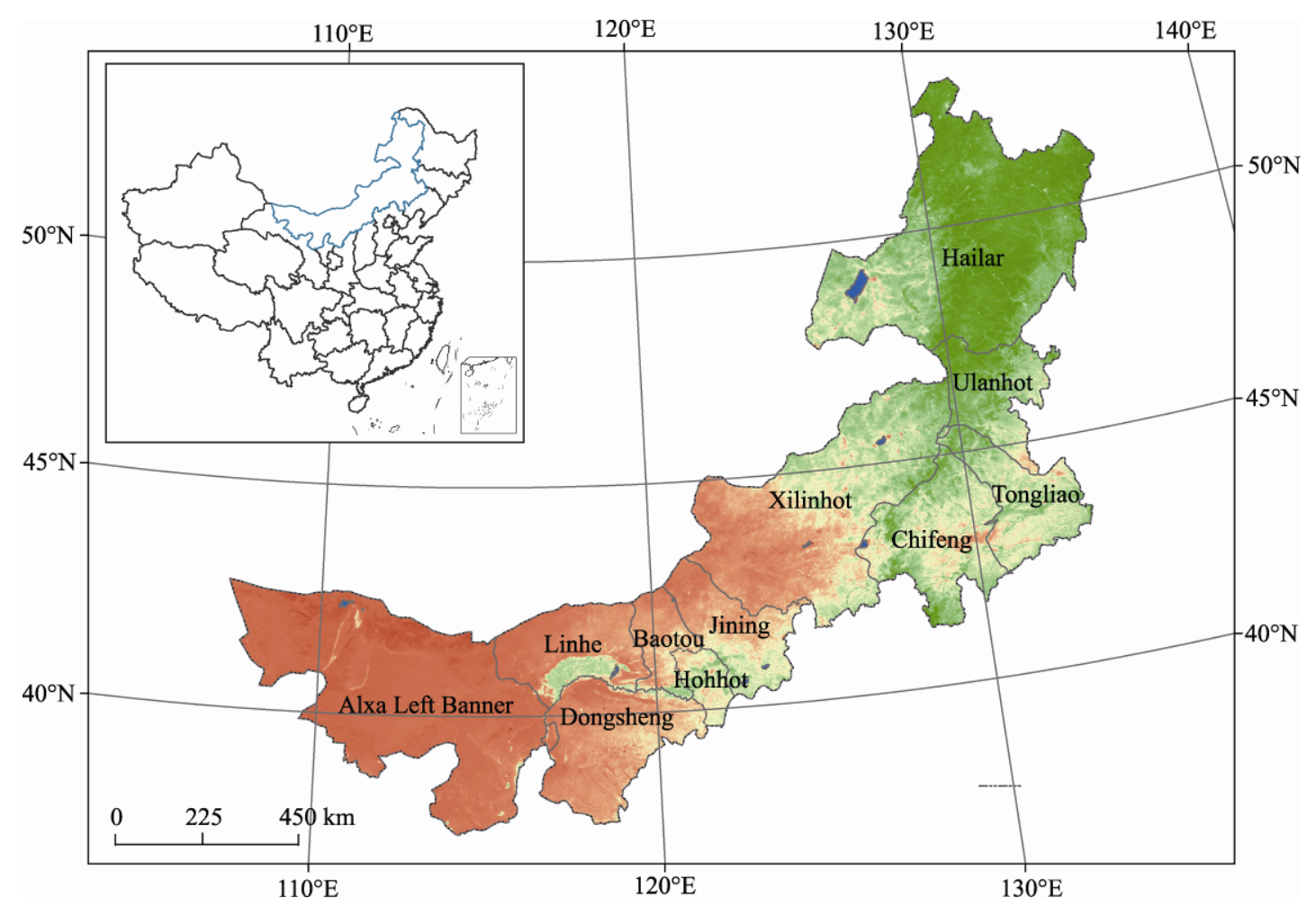

Fig. 1 Location of Inner Mongolia and the mean Normalized Difference Vegetation Index (NDVI) in 2011 
decreasing from higher to lower altitudes (Jiang et al., 2003). Precipitation varies greatly from $50 \mathrm{~mm}$ in the west to more than $450 \mathrm{~mm}$ in the east, with approximately $80 \%$ occurring in the growing season from May to September. In the western part of the study area, vegetation coverage and biomass production are lower due to scare precipitation. The main soil types in Inner Mongolia are sandy clay loam, clay loam and sandy loam.

\subsection{Data source}

The daily meteorological data used in this study, including snow depth, daily precipitation, wind velocity and mean air temperature, were obtained from China Meteorological Administration (CMA). Then, the meteorological data were interpolated into grid cells with a spatial resolution of $1 \mathrm{~km} \times 1 \mathrm{~km}$ using the ordinary Kriging interpolation of ArcGIS 10.1. The data of soil organic carbon and soil particle size distribution were obtained from the Institute of Soil Science, Chinese Academy of Sciences (Jing et al., 2005). The third-generation dataset of Global Inventory Modeling and Mapping Studies (GIMMS) NDVI was derived from the Advanced Very High Resolution Radiometer (AVHRR; http://daac.gsfc.nasa.gov), and the dataset of MODIS NDVI was obtained from the National Aeronautics and Space Administration (NASA) Earth Observing System (Dobrowski et al., 2005). The Digital Elevation Model (DEM $90 \mathrm{~m}$ ) used in this study was the three-arc-second data available at http://srtm.csi.cgiar.org. The data of land use type were supplied by the Institute of Remote Sensing and Digital Earth, Chinese Academy of Sciences, from 1:100,000 standard maps (Li et al., 2004). The field survey data (263 sites), applied to test the accuracy of the estimated wind erosion, were obtained in July 2011.

\subsection{Calculation of index variables}

The complexity of the wind erosion model is derived from the fact that the factors controlling soil erodibility vary in degree of influence through space and time. In addition, quantitative estimation of wind erosion is difficult on a large scale. A dry and windy climate is essential to the process of soil wind erosion. However, the climate of Inner Mongolia in winter is significantly affected by the cold current of Mongolia-Siberian system. This region is characterized by its loose soil surface, wildly distributed desert, strong winds and low vegetation coverage, all of which exacerbate the process of soil wind erosion. However, few methods have been developed thus far to quantitatively estimate the soil wind erosion on a large scale. Five critical parameters including the number of snow cover days, soil erodibility, aridity, vegetation index and wind field intensity were selected to comprehensively evaluate the quantity of soil wind erosion. The spatial resolution of all of the datasets, which consist of images of the five indices, was $1 \mathrm{~km} \times 1 \mathrm{~km}$.

\subsubsection{Number of snow cover days}

Accumulated snow can significantly reduce the area of the top soil layer exposed to wind. Wind erosion did not occur when the fraction of snow cover reached $60 \%$ (Wei et al., 2002). Moreover, melted snow, influenced by an increase in temperature, results in water saturation in the shallow surface soil. This melt water can rearrange the physical and chemical structure of soil particles and change the soil bulk density and permeability, which increases the stability of the surface soil (Mostaghimi et al., 1988; Qi et al., 2008). A snow cover day was defined as that when the snow depth reached $0.5 \mathrm{~cm}$.

\subsubsection{Soil erodibility}

Soil erodibility, the susceptibility of soil particles to detachment and transportation by erosive agents of wind and water, is an essential parameter required for the prediction of soil erosion (Bryan, 1968; Geeves et al., 2000). This parameter is defined as the amount of soil loss per unit exogenic force or erosivity, which is controlled by the intrinsic properties of soil (Raupach and $\mathrm{Lu}, 2004)$. It is generally considered as an inherent soil property with a constant value for a given soil type (Webb and McGowan, 2009). In this study, the data of soil organic carbon and soil particle size distribution were used to calculate soil erodibility:

$$
\begin{aligned}
& S E=\left\{0.2+0.3 \exp \left[-0.0256 S_{a}\left(1-\frac{S_{i}}{100}\right)\right]\right\} \times \\
& \left(\frac{S_{i}}{C_{1}+S_{i}}\right)^{0.3} \times\left[1-\frac{0.25 C}{C+\exp (3.72-2.95 C)}\right] \times . \\
& {\left[1-\frac{0.7 \mathrm{~S}_{n}}{S_{n}+\exp \left(-5.51-22.9 \mathrm{~S}_{n}\right)}\right]}
\end{aligned}
$$

Where $S E$ is soil erodibility; $S_{a}(0.050-2.00 \mathrm{~mm}), S_{i}$ $(0.002-0.050 \mathrm{~mm})$ and $C_{l}(<0.002 \mathrm{~mm})$ refer to sand 
fraction (\%), silt fraction (\%) and clay fraction (\%), respectively; $C$ is soil organic carbon content (\%); and $S_{n}$ is equal to $1-S_{\mathrm{a}} / 100$.

\subsubsection{Aridity}

Aridity can indicate a considerable water deficit in the top layer of the soil (Rana et al., 2005). Wind can easily remove and transfer soil particles when the top layer of the soil is totally dry and has lost the water content necessary for bonding (Hagen, 1991). Aridity has significant relations with precipitation and temperature.

$$
D=0.16 \sum \geq 10^{\circ} \mathrm{C} / P \text {. }
$$

Where $D$ is the aridity index, $\quad \sum \geq 10^{\circ} \mathrm{C}$ refers to the sum of air temperature that is higher than $10^{\circ} \mathrm{C}$ in one year, and $P$ is the sum of precipitation during the period in which the air temperature is higher than $10^{\circ} \mathrm{C}$.

\subsubsection{Wind field intensity}

Wind field intensity is a main contributor to wind erosion, particularly in arid and semi-arid regions (Grini and Zender, 2004). Soil wind erosion is largely affected by wind velocity and critical friction wind velocity on the ground surface (Li et al., 2003). Furthermore, wind speed has a positive relation with wind erosion, and wind can remove soil particles when the wind velocity reaches a certain critical speed. Many studies reported that critical wind velocities were influenced by soil particle size, moisture content and ground hardness (Bryan, 1968; Geeves et al., 2000; Chappell et al., 2006). In this study, a critical wind velocity of $6 \mathrm{~m} / \mathrm{s}$ was adopted to calculate the number of days.

\subsubsection{Vegetation index}

Green vegetation cover on the land surface is of great importance in regulating surface wind and hydrological processes because it can mitigate the erosion forces of wind and rainfall (Zhang and Gao, 2006; Chen et al., 2007). The Normalized Difference Vegetation Index (NDVI) is a measure of vegetation activity and biomass (Huete and Tucker, 1991). The time-series GIMMS NDVI data of 1985 used in this study is at a spatial resolution of $8 \mathrm{~km} \times 8 \mathrm{~km}$ with a 15-day interval. The spatial resolution of Moderate Resolution Imaging Spectroradiometer (MODIS) NDVI of 2011 is $1 \mathrm{~km} \times 1 \mathrm{~km}$. To confirm the spatial resolution consistency of the two datasets, the GIMMS NDVI data were converted into grid cells at a resolution of $1 \mathrm{~km} \times 1 \mathrm{~km}$ by using the nearest neighbour assignment resampling algorithm with ArcGIS 10.1. Then, the monthly NDVI data were obtained by using the maximum value composite method to minimize the effects of cloud contamination, atmospheric effects and solar zenith angle (Stow et al., 2004). Finally, the average annual vegetation cover was calculated on the basis of the monthly NDVI data.

\subsection{Estimation model of wind erosion}

The evaluation of wind erosion requires integration of multiple factors to obtain a comprehensive index. However, most previous studies only used the analytic hierarchy process (AHP) or the entropy method to calculate the weight of each index. The results of AHP are influenced mainly by subjective factors whereas the entropy method often ignores the prior knowledge of experts (Zhang et al., 2006). In this study, the two methods were integrated to obtain the weights of indices so that both the prior knowledge of experts and objective information of each index could be considered. Then, the improved AHP and a weighted summation method were combined to calculate the comprehensive evaluation index by using the following formulae:

$$
\begin{gathered}
E M_{i 0}=-\frac{1}{m} \sum_{j=1}^{m} I_{i j} \ln I_{i j}, \\
E M_{i}=\left(1-E M_{i 0}\right) / \sum_{i=1}^{n}\left(1-E M_{i 0}\right), \\
W_{A H P-E M, i}=\frac{E M_{i} A H P_{i}}{\sum_{i=1}^{n} E M_{i} A H P_{i}}, \\
\sum_{i=1}^{n} W_{A H P-E M, i} I_{i} \\
\sum_{i=1}^{n} W_{A H P-E M, i}
\end{gathered}
$$

Where $E M_{i 0}$ is the weight obtained by using the entropy method, $E M_{i}$ is the normalized weight of each factor, $I_{i j}$ is the value of pixel $j$ for index $i, m$ is number of pixels for index $i, W_{A H P-E M, i}$ is the integrated modified weight of all indices, $A H P_{i}$ is the weight obtained by using the AHP method, $I_{i}$ is the dimensionless value of each index, $n$ refers to the number of 
impact factors and $I$ is the comprehensive evaluation index.

Firstly, the datasets of the five factors were standardized to eliminate the influence of unit difference among the variables. Secondly, the $E M_{i}$ was obtained by the using entropy method (Eqs. 3 and 4). Thirdly, the weight of each factor was calculated by AHP (Tables 1 and 2) according to its relative effects on the vulnerability of wind erosion. Finally, the $E M_{i}$ was assumed into the calculation of $W_{A H P-E M, \mathrm{i}}$ with $A H P_{i}$ (Eqs. 5 and 6). The weight of each index is listed in Table 3.

Table 1 Scale of binary comparison

\begin{tabular}{cl}
\hline Degree of importance & \multicolumn{1}{c}{ Definition } \\
\hline 1 & Equal importance of two elements \\
5 & Weak importance of an element in comparison to the other one \\
7 & Strong importance of an element in comparison to the other one \\
9 & Certified importance of an element in comparison to the other one \\
$2,4,6,8$ & Absolute importance of an element in comparison to the other one \\
Intermediate values between two appreciations \\
Reciprocal values of the previous appreciation
\end{tabular}

Table 2 Relative weights of factors of wind erosion for analytic hierarchy process (AHP)

\begin{tabular}{lccccc}
\hline Evaluation index & $(1)$ & $(2)$ & (3) & (4) & (5) \\
\hline (1) Snow cover days & 1 & & & & \\
(2) Soil erodibility & 15 & 1 & & & \\
(3) Aridity & $1 / 3$ & 3 & 1 & & \\
(4) Days of $>6 \mathrm{~m} / \mathrm{s}$ wind & $1 / 2$ & 5 & 2 & 1 & \\
field intensity & 1 & 5 & 3 & 1 & 1 \\
(5) Vegetation index & &
\end{tabular}

Table 3 Weights of AHP, entropy method and the improved AHP

\begin{tabular}{lccc}
\hline \multirow{2}{*}{ Evaluation index } & \multicolumn{3}{c}{ Weight } \\
\cline { 2 - 4 } & $\mathrm{AHP}_{\mathrm{i}}$ & $\mathrm{EM}_{\mathrm{i}}$ & $\mathrm{AHP}^{\mathrm{E}} \mathrm{EM}_{\mathrm{i}}$ \\
\hline Snow cover days & 0.24 & 0.16 & 0.19 \\
Soil erodibility & 0.15 & 0.29 & 0.22 \\
$\begin{array}{l}\text { Aridity } \\
\begin{array}{l}\text { Days of }>6 \mathrm{~m} / \mathrm{s} \\
\text { field intensity }\end{array}\end{array}$ & 0.18 & 0.07 & 0.06 \\
Vegetation index & 0.20 & 0.22 & 0.23 \\
\hline
\end{tabular}

\section{Results and discussion}

\subsection{Classification of wind erosion intensity and accuracy assessment}

The five indices shown in Table 1 were integrated to evaluate wind erosion for 1998 and 2011. In this study, the wind erosion intensity was divided into six cate- gories by using the Natural Breaks function of ArcGIS 10.1, which effectively showed the contrast of distinct categories without ignoring the subtle differences. The six categories included no erosion $(\mathrm{I}<0.28)$, slight erosion $(0.28<\mathrm{I}<0.34)$, mild erosion $(0.34<\mathrm{I}<0.40)$, moderate erosion $(0.40<\mathrm{I}<0.46)$, intensive erosion $(0.46<\mathrm{I}<0.54)$ and severe erosion $(0.54>\mathrm{I})$. The spatial patterns of wind erosion in 1985 and 2011 were shown in Fig. 2.

The basic error matrices (Eqs. 7 and 8; Bruin, 2000) and the precision index were applied to test the accuracy of the estimated results. To confirm the validity of the sampling points in 2011, 263 sites were chosen from regions with different landforms, slopes, soil types and land use types (Table 4). The error matrix of the calculated erosion category and the field survey results were listed in Table 5.

$$
\begin{gathered}
p_{i+}=\sum_{j=1}^{n} p_{i j}, \\
p_{+j}=\sum_{i=1}^{n} p_{i j} .
\end{gathered}
$$

Where $n$ represents the number of categories, $P_{i j}$ is the number of the evaluated category $i$ and field survey category $j$ that both occur, $P_{i+}$ is the sum of the evaluated category $i$ and $P_{+j}$ is the sum of field survey category $j$. 


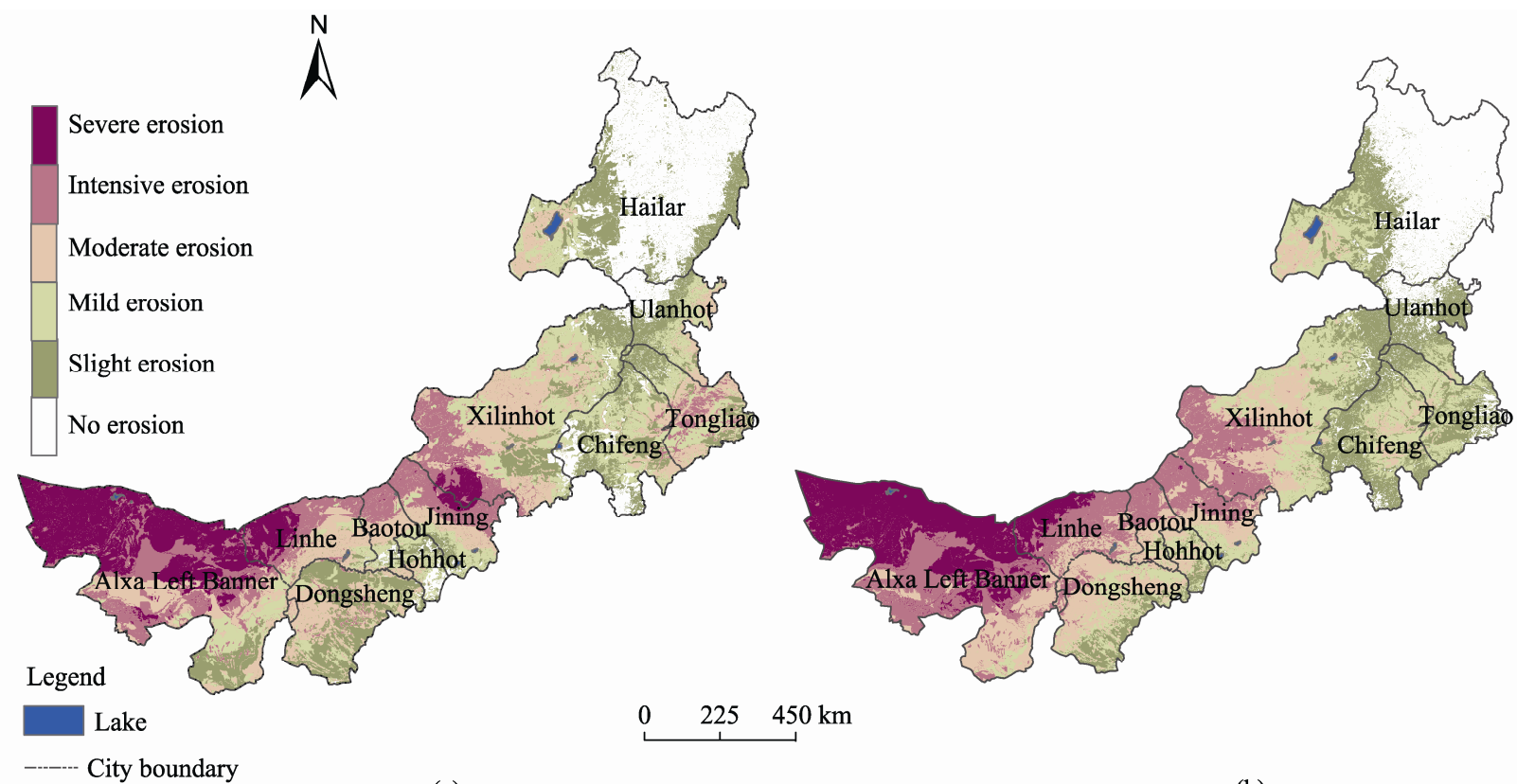

(a)

(b)

Fig. 2 Changes in wind erosion intensity in Inner Mongolia. (a) wind erosion intensity of 1985, (b) wind erosion intensity of 2011.

Table 4 Error matrix of wind erosion categories for 2011

\begin{tabular}{ccccccc}
\hline \multirow{2}{*}{ Wind erosion category } & \multicolumn{5}{c}{ Wind erosion results } \\
\cline { 2 - 7 } & Slight erosion & Mild erosion & Moderate erosion & Intensive erosion & Severe erosion & Sum \\
\hline Slight erosion & 87 & 7 & 1 & 2 & 1 & 98 \\
Mild erosion & 3 & 37 & 2 & 3 & 5 & 50 \\
Moderate erosion & 5 & 8 & 44 & 3 & 2 & 62 \\
Intensive erosion & 0 & 1 & 3 & 0 & 3 & 30 \\
Severe erosion & 1 & 3 & 0 & 31 & 55 & 263 \\
Sum & 96 & 56 & 50 & & 23 \\
\hline
\end{tabular}

Table 5 Precision index of wind erosion categories

\begin{tabular}{ccccc}
\hline Precision test & User accuracy & Commission & Cartographic accuracy & Omission \\
\hline Slight erosion & 0.91 & 0.08 & 0.89 & 0.11 \\
Mild erosion & 0.66 & 0.34 & 0.74 & 0.39 \\
Moderate erosion & 0.88 & 0.12 & 0.71 & 0.32 \\
Intensive erosion & 0.74 & 0.26 & 0.77 & 0.39 \\
Severe erosion & 0.77 & 0.23 & 0.90 & 0.22 \\
\hline
\end{tabular}

In Table 5, the cartographic precisions of all categories ranged from 0.71 to 0.90 , which indicated significant credibility in the evaluation of wind erosion. Furthermore, the classification results were in agreement with the actual erosion levels. Severe erosion had the best evaluation precision, followed by slight erosion. The accuracies of mild and moderate erosion were much lower. To summarize, the wind erosion model of Inner Mongolia was effective and accurate with an overall precision of $81.07 \%$.

\subsection{Spatial differentiation of wind erosion}

As shown in Fig. 2, wind erosion widely existed in Inner Mongolia with an area of $90 \times 10^{4} \mathrm{~km}^{2}$, covering approximately $80 \%$ of the region. The erosion was distributed continuously in the midwestern region. 
Zones of no erosion were concentrated mainly in the middle of Hailar city and in the northern part of Ulanhot city. The spatial disparities of wind erosion zones differed significantly. The zone of slight erosion was distributed discontinuously in the southern and western parts including Dongsheng city and Chifeng city. The zone of severe erosion was concentrated mostly in Alxa Left Banner, northwestern Linhe city and southwestern Xilinhot city. Moderate and mild erosion zones were distributed between the zones of severe erosion and slight erosion.

Among all levels of wind erosion intensity in 1985, the moderate erosion zone covered a largest area of $22.61 \times 10^{4} \mathrm{~km}^{2}$, accounting for $19.77 \%$ of the study area. The zones of no, slight, mild, intensive and severe erosion were $21.61 \times 10^{4}, 21.60 \times 10^{4}, 19.49 \times 10^{4}$, $22.61 \times 10^{4}$ and $22.61 \times 10^{4} \mathrm{~km}^{2}$, respectively. However, in 2011, the zone of mild erosion was the largest with an area of $20.87 \times 10^{4} \mathrm{~km}^{2}$, accounting for $18.25 \%$ of the study area, followed by zones of moderate $\left(20.33 \times 10^{4} \mathrm{~km}^{2}\right)$ and intensive $\left(20.20 \times 10^{4} \mathrm{~km}^{2}\right)$ erosion. The severe erosion zone covered the smallest region with an area of $13.31 \times 10^{4} \mathrm{~km}^{2}$.

During the study period, wind erosion has aggravated over the entire region of Inner Mongolia as evidenced by the decreases in areas of no and slight erosion and increases in areas of mild, intensive and severe erosion (Table 6). In detail, the eroded regions were distributed mainly in southern Alxa Left Banner, northern Dongsheng city and western Xilinhot city. On the contrary, the zones of decreased erosion intensity were concentrated mainly in eastern Hailar city, Tongliao city and eastern Xilinhot city.

Table 6 Areas and area ratios of different wind erosion categories for 1985 and 2011

\begin{tabular}{lccccc}
\hline \multirow{2}{*}{$\begin{array}{c}\text { Wind erosion } \\
\text { category }\end{array}$} & \multicolumn{2}{c}{1985} & & \multicolumn{2}{c}{2011} \\
\cline { 2 - 3 } \cline { 5 - 6 } & $\begin{array}{c}\text { Area } \\
\left(\times 10^{4} \mathrm{~km}^{2}\right)\end{array}$ & $\begin{array}{c}\text { Area ratio } \\
(\%)\end{array}$ & & $\begin{array}{c}\text { Area } \\
\left(\times 10^{4} \mathrm{~km}^{2}\right)\end{array}$ & $\begin{array}{c}\text { Area ratio } \\
(\%)\end{array}$ \\
\hline No erosion & 21.61 & 18.90 & & 19.73 & 17.25 \\
Slight erosion & 21.60 & 18.89 & & 19.90 & 17.40 \\
Mild erosion & 19.49 & 17.05 & & 20.87 & 18.25 \\
Moderate erosion & 22.61 & 19.77 & & 20.33 & 17.78 \\
Intensive erosion & 15.75 & 13.78 & & 20.20 & 17.67 \\
Severe erosion & 13.27 & 11.61 & 13.31 & 11.64 \\
\hline
\end{tabular}

Figure 3 shows that the process of wind erosion changed significantly for each category. During 1985-2011, serve erosion was the most stable category with $85.95 \%$ unchanged, followed by the category of no erosion ( $74.89 \%$ unchanged). However, the category of mild erosion showed the most dramatic change with only $42.12 \%$ unchanged, whereas the other areas showed slight erosion. There was $27.83 \%$ of slight erosion turning into higher categories of erosion with $43.93 \%$ of this category unchanged. Intensive erosion was the second most stable category with $72.37 \%$ unchanged whereas the rest mainly changed to severe erosion. A dramatic change in the category of moderate erosion was noted with only $44.48 \%$ unchanged.

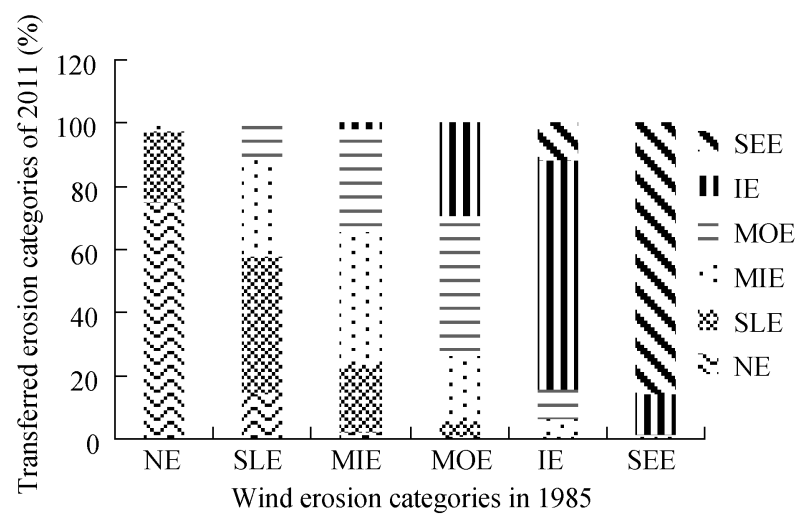

Fig. 3 Change matrix of the areas of different wind erosion categories in Inner Mongolia during 1985-2011. NE, no erosion; SLE, slight erosion; MIE, mild erosion; MOE, moderate erosion; $\mathrm{IE}$, intensive erosion; SEE, severe erosion.

\subsection{Change intensity of wind erosion}

To more effectively monitor the changes in wind erosion intensity, the change intensity (CI) of wind erosion between 1985 and 2011 was obtained by using the subtraction method through the raster calculator of ArcGIS10.1. According to the natural conditions in the study area, the change intensity of wind erosion in Inner Mongolia was divided into seven grades including mild decrease (MD; $\mathrm{CI}<-0.10)$, slight decrease (SD; $-0.10<\mathrm{CI}<-0.05$ ), stable (ST; $-0.05<\mathrm{CI}<0.05$ ), slight increase (SLI; $0.05<\mathrm{CI}<0.10$ ), mild increase (MI; $0.10<\mathrm{CI}<0.15$ ), intensive increase (II; $0.15<\mathrm{CI}<0.20$ ) and severe increase (SI; $0.20>\mathrm{CI}$ ). The distribution of the various grades of change intensity was shown in Fig. 4. A distinct spatial differentiation of each grade 


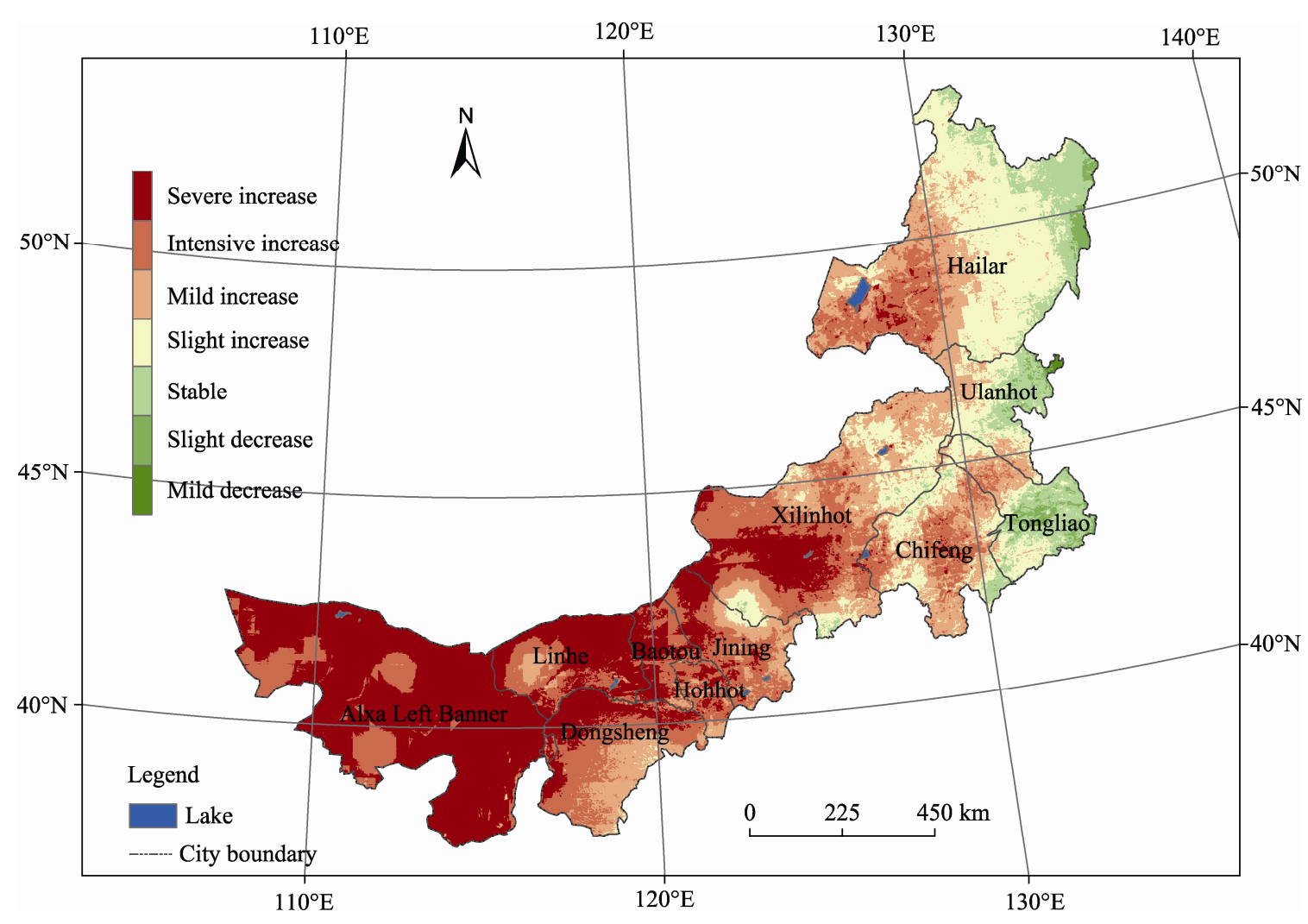

Fig. 4 Classification map of change intensity of wind erosion in Inner Mongolia during 1985-2011

of change intensity occurred during 1985-2011. Severe increase was the most widely distributed grade with an area of $34.72 \times 10^{4} \mathrm{~km}^{2}$, concentrated mainly in western regions such as Alxa Left Banner, Linhe city and southern Xilinhot city. The intensive increase zone was distributed mainly near the severe decrease region with an area of $26.4 \times 10^{4} \mathrm{~km}^{2}$, accounting for $24.68 \%$ of the study area, and included midwestern Dongsheng city, Chifeng city and eastern Hailar city. The slight increase zone was concentrated mostly in the eastern region. In addition, the decrease (slight decrease and mild decrease) and stable zones were distributed mainly in northeastern Hailar city, eastern Ulanhot city and northern Tongliao city, accounting for approximately $2.23 \%$ of the study area. Therefore, it was proved that during 1985-2011, wind erosion had aggravated in the entire region of Inner Mongolia.

\subsection{Relations between change intensity of wind erosion and its driving forces}

2.4.1 Relation between change intensity of wind erosion and land use type

To examine the relation between intensity change of wind erosion and land use type, we selected eight typical land use types, i.e. evergreen needle-leaf forest (ENF), deciduous broadleaf forest (DBF), open shrubland (OS), woody steppe (WS), steppe (ST), grassland (GRA), cropland (CRO) and barren or sparsely vegetation (BSV) (Fig. 5). Figure 6 shows the significant differences in change intensity of wind erosion among all land use types. The region dominated by BSV had the largest increased intensity with a mean value of 0.17 , which was classified as severe increase. This is because barren or sparse vegetation land was distributed mainly in the western part with scare precipitation. Global warming has accelerated during the past several decades, resulting in increased temperatures and decreased rainfall (Knapp and Smith, 2001; Dunne et al., 2004). Thus, the vegetation productivity and soil moisture were negatively influenced by the process of climate change, and the decrease in vegetation coverage and soil moisture led to aggravation of wind erosion. Moreover, the mean change intensities for OS and GRA were 0.11 and 0.09 , belonging to the grades of intensive and moderate increases, respectively. These results occurred because the average annual precipitation in this semi-arid zone was less than $150 \mathrm{~mm}$. 
Along with the decreased precipitation and rising temperature, human activities such as deforestation and overgrazing exerted substantial influences on the eco-environment (Zhang et al., 2007). These activities decreased the vegetation coverage and destroyed the physical and chemical structures of the topsoil. Both natural and anthropogenic factors aggravate the process of wind erosion. For the zones dominated by ENF, DBF, WS, SA and CRO, the mean change intensities were $0.03,0.02,0.04,0.03$ and 0.02 , respectively. These areas had abundant annual precipitation ranging from 300 to $400 \mathrm{~mm}$, and the vegetation coverage was high. However, the fluctuation range of change intensity for GRA was the largest due to the wide distribution and low vegetation cover of this land use type. OS, showing the second highest range, was concentrated mainly between deserts and GRA, in which the ecological and environmental conditions changed significantly. On the contrary, the change intensity of DBF and ENF had smaller fluctuation ranges because these land use types were distributed in the northeast with high vegetation coverage and abundant precipitation. Therefore, by comparing the mean value and fluctuation range of change intensity in each land use type, we determined that during the study period, regions dominated by BSV were the most severely eroded areas, followed by those of OS. With the largest fluctuation range, the zones occupied by GRA would have the highest potential for the most dramatic change in the future.

2.4.2 Relation between change intensity of wind erosion and land slope

The negative relation between change intensity of wind erosion and land slope was significant. The data of land slope were obtained from the Digital Elevation Model (DEM $90 \mathrm{~m}$ ) by ArcGIS 10.1 (Fig. 7). In detail, the slope range of $<3^{\circ}$ showed the largest change intensity and fluctuation range with values of 0.12 and 0.45 , respectively, followed by slope ranges of $3^{\circ}-6^{\circ}$ (Fig. 8). On the contrary, the smallest mean change intensity and fluctuation range of wind erosion

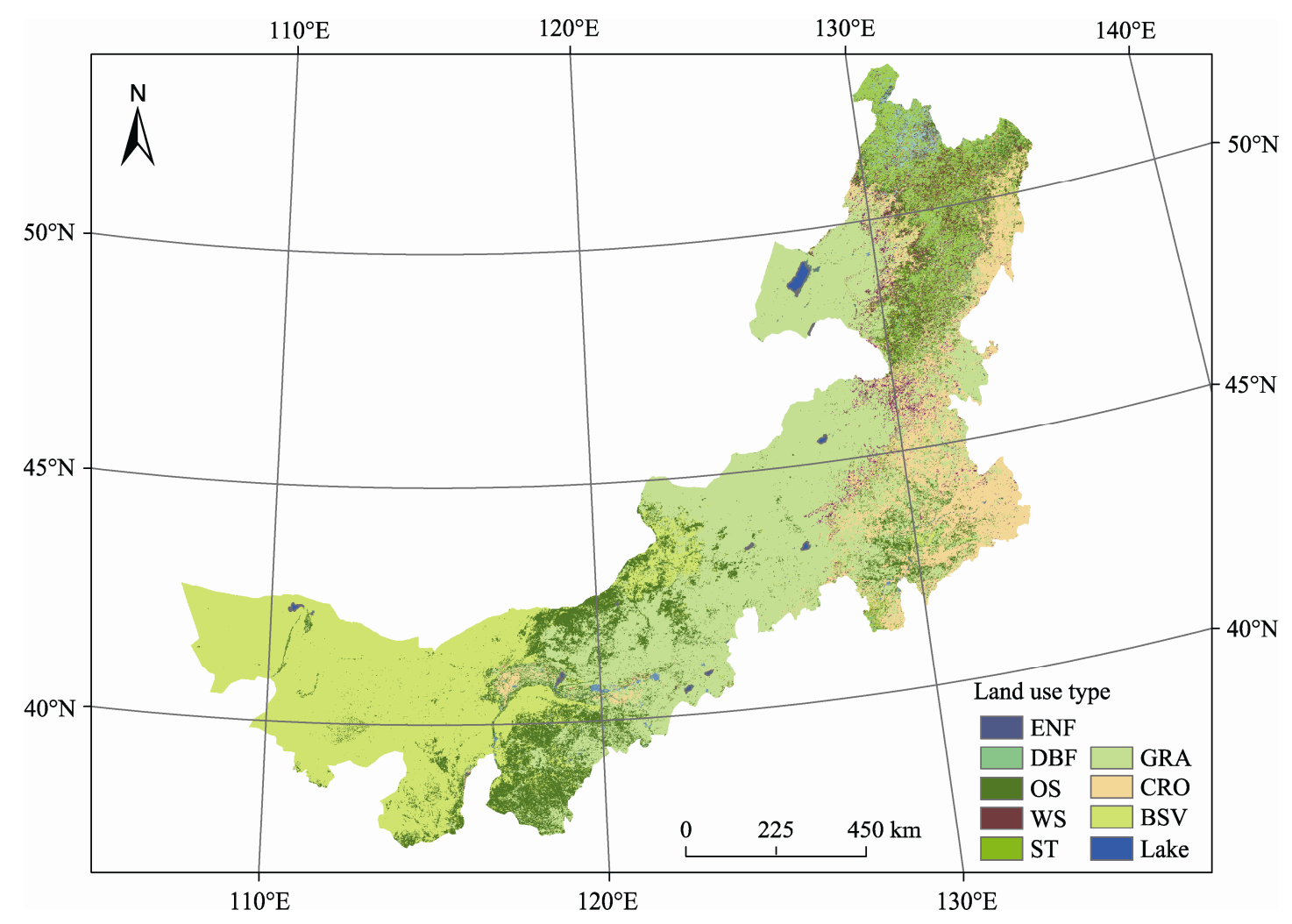

Fig. 5 Distribution of typical land use types in Inner Mongolia. ENF, evergreen needle-leaf forest; DBF, deciduous broadleaf forest; OS, open shrubland; WS, woody steppe; ST, steppe; GRA, grassland; CRO, cropland; BSV, barren or sparsely vegetation. 


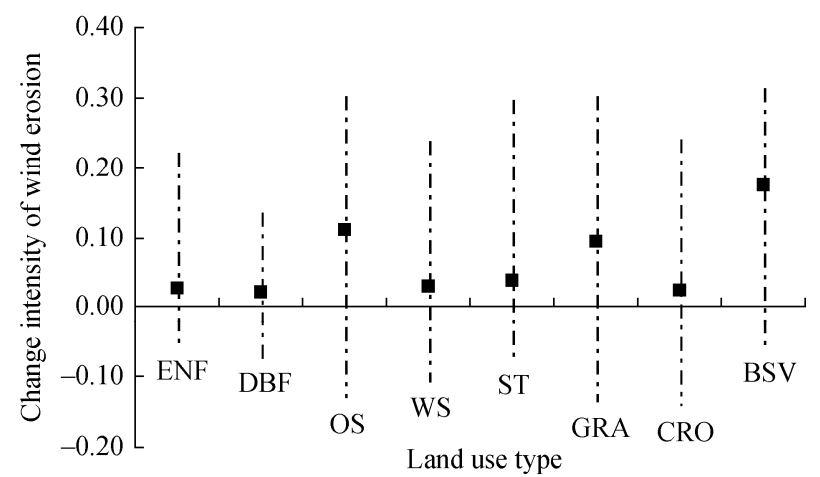

Fig. 6 Change intensity of wind erosion for each land use type. The top of each line represents the maximum value of erosion change intensity for each land use type whereas the bottom shows the minimum value. Black squares refer to the mean values of change intensity, and the length of each line refers to the fluctuation range of erosion change intensity.

occurred in the slope range of $>12^{\circ}$. Many studies suggested that land slope had a negative relation with soil depth (Ilan et al., 2008; Wood et al., 2008). Therefore, these phenomena occurred because the degree of wind erosion was restrained by the rare occurrence of soil at larger slopes. In addition, to- pographic relief and surface fragmentation both increase with the raise of slopes, which resulted in a significant increase of surface roughness. The soil erodibility had a strong positive relation with surface roughness (Zhou and Shangguan, 2006). The change intensity of wind erosion was smaller in larger slope ranges.

2.4.3 Relation between change intensity of wind erosion and soil type

Nine typical soil types were selected to analyze the relations between change intensity of wind erosion and soil type. As shown in Fig. 9, these soil types included calcic chernozems (CC), calcaric fluvisols (CF), calcaric arenosols (CA), calcic kastanozems (CK), eutric cambisols (EA), luvic gypsisols (LG), haplic luvisols (HL), haplic arenosols (HA) and haplic kastanozems (HK).

The difference in change intensity of wind erosion was large among the soil types (Fig. 10). The change intensity of wind erosion for LG was the largest with a mean value of 0.2 , which belonged to the grade of

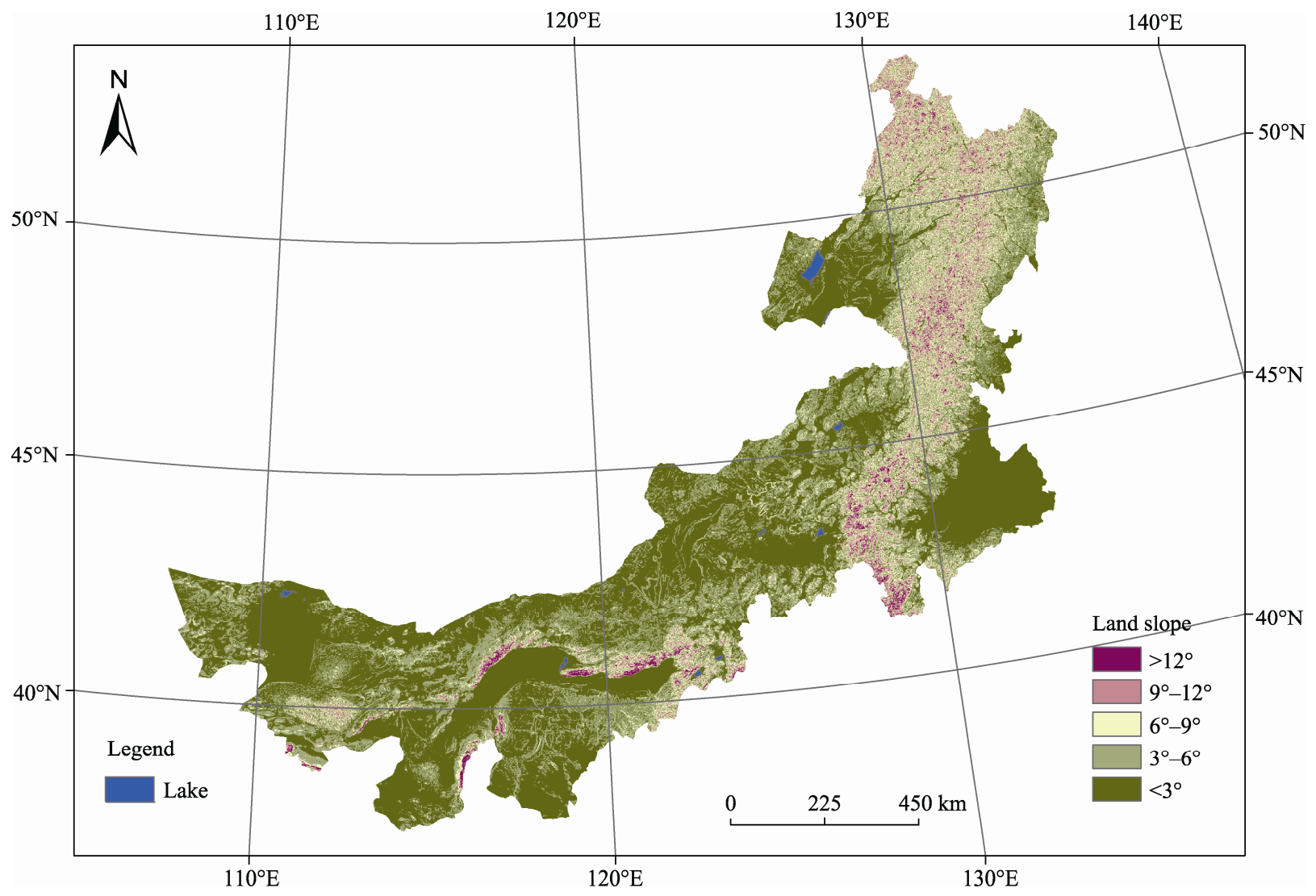

Fig. 7 Distribution of land slopes in Inner Mongolia 


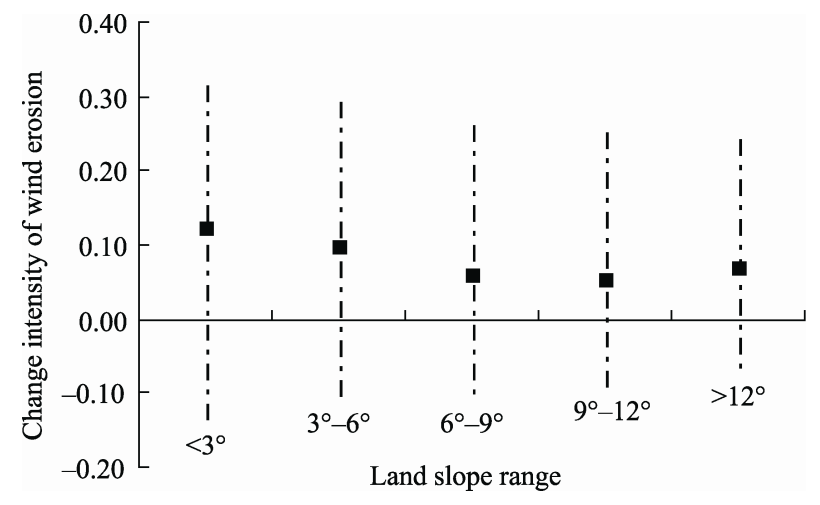

Fig. 8 Change intensity of wind erosion at different land slopes. The top of each line represents the maximum value of erosion change intensity for each land slope range whereas the bottom shows the minimum value. Black squares refer to the mean values of change intensity, and the length of each line refers to the fluctuation range of erosion change intensity.

severe increase. On the contrary, the CF had the smallest change intensity of wind erosion with a mean value of -0.06 . The change intensities of wind erosion for both HL and EC had smaller mean values of 0.02 . Soil erodibility, affected by the inherent properties of the soil, reflects the vulnerability of the soil itself to erosion (Zhou and $\mathrm{Wu}, 1993$; Jiang et al., 1995). In addition, $\mathrm{CaCO}_{3}$ in the top layer of the soil can cement soil particles to form large clumps, which can largely decrease soil erodibility (Zhao and Shi, 2003). Therefore, the change intensities of wind erosion for $\mathrm{CC}, \mathrm{CF}, \mathrm{CA}, \mathrm{CK}$ and EC were significantly smaller than those for LG and HA. Many studies have reported that the distribution of different soil types with particle sizes of $0-1 \mathrm{~cm}$ was important for determining soil erodibility (Mutchler and Carter, 1983; Miao et al., 2004). Under the same conditions, the critical wind velocity for wind erosion of sandy soil was larger than that of loamy soil. Moreover, soil erodibility decreases with an increase in soil particle size (Vaezi et al., 2008). To summarize, among all soil types, $\mathrm{HL}$ and $\mathrm{CF}$ showed the strongest resistance to wind erosion.

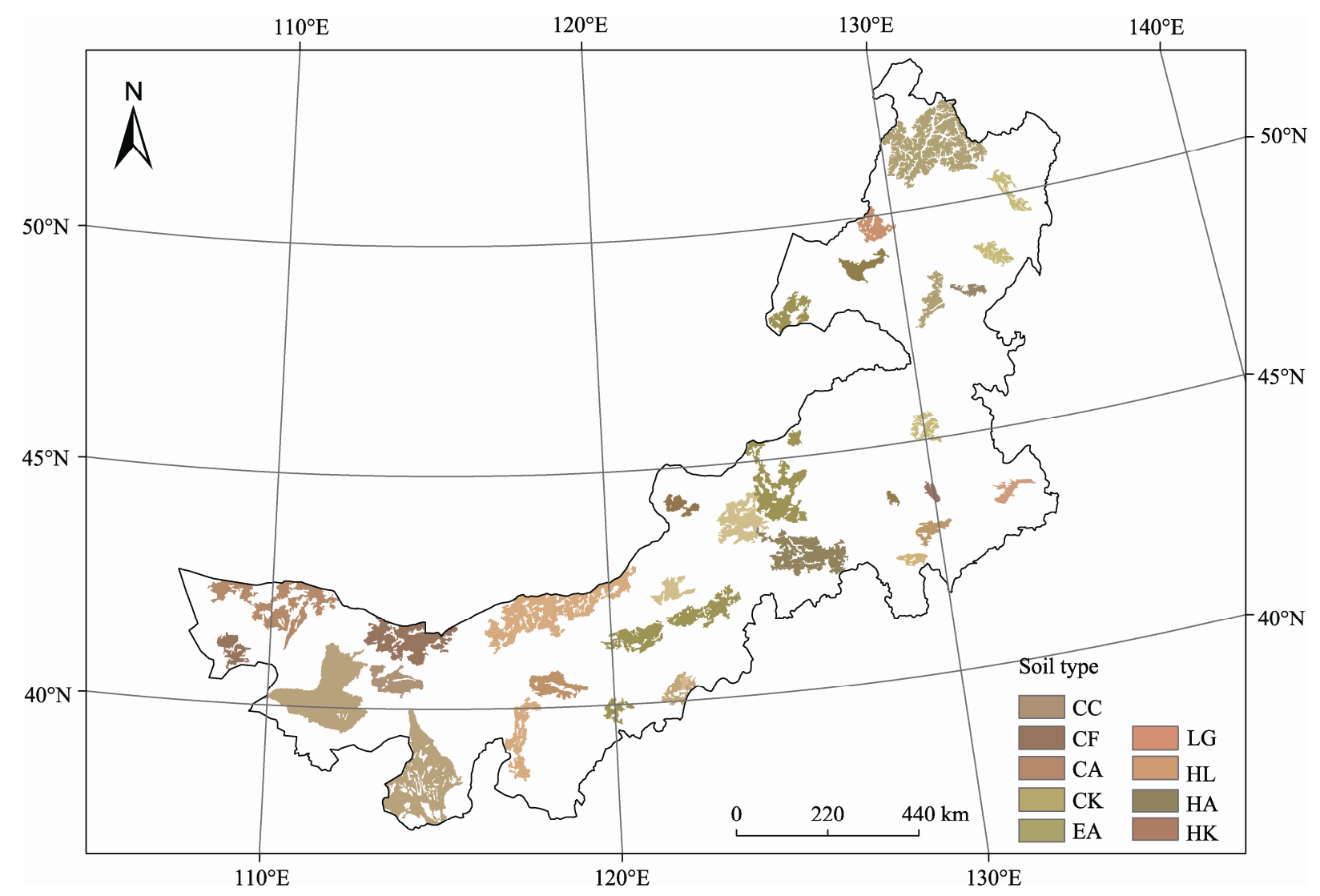

Fig. 9 Distribution of typical soil types in Inner Mongolia. CC, calcic chernozems; CF, calcaric fluvisols; CA, calcaric arenosols; CK, calcic kastanozems; EA, eutric cambisols; LG, luvic gypsisols; HL, haplic luvisols; HA, haplic arenosols; HK, haplic kastanozems. 


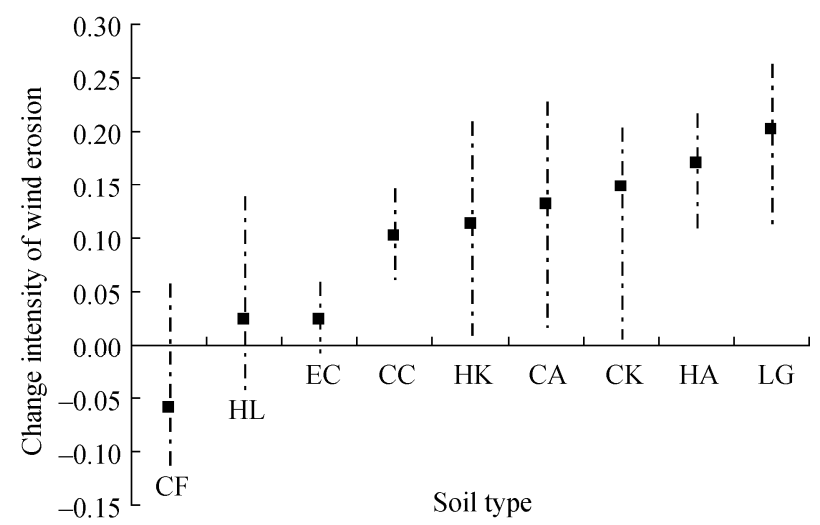

Fig. 10 The change intensity of wind erosion for different soil types. The top of each line represents the maximum value of erosion change intensity for each soil type whereas the bottom shows the minimum value. Black squares refer to the mean values of change intensity, and the length of each line refers to the fluctuation range of erosion change intensity.

\section{Conclusions}

The new estimation model of wind erosion showed strong operationality and practicability in this study. The estimated results were proved to be more accurate through precision evaluation by using field survey data.

Wind erosion widely existed in Inner Mongolia with an area of approximately $90 \times 10^{4} \mathrm{~km}^{2}$, accounting for $80 \%$ of the study region. The intensive and severe erosion zones were mainly distributed in the midwestern region, whereas the slight and mild erosion zones were concentrated in the eastern area. During 1985-2011, wind erosion has aggravated over the entire Inner Mongolia, which was indicated by enlarged zones of severe, intensive and mild erosion. Because of the natural and anthropogenic factors, a distinct spatial differentiation of change intensity of wind erosion occurred during the study period. The zones of increased intensity, indicated by severe, intensive and mild erosion, were mostly distributed in the midwestern region whereas the zones of decreased and stable erosion were mainly concentrated in eastern part of Inner Mongolia. Regions dominated by barren or sparse vegetation land were the most severely eroded, followed by that of open shrubbery. In addition, zones covered by grass would have the highest potential for the most dramatic changes of wind erosion in the future because of their large fluctuation ranges of change intensity. Moreover, a significantly negative relation was noted between change intensity and land slope. The relation between soil type and change intensity differed with the content of $\mathrm{CaCO}_{3}$ and the surface composition of sandy, loamy and clayey soils with particle sizes of $0-1 \mathrm{~cm}$. However, further studies based on GIS and RS should be conducted at a large regional scale to clarify the mechanisms underlying the process of wind erosion and to strengthen the precision of evaluation.

\section{Acknowledgements}

This work was supported by the National Natural Science Foundation of China (41201441, 41371363, 41301501), Foundation of Director of Institute of Remote Sensing and Digital Earth, Chinese Academy of Science (Y4SY0200CX) and Guangxi Key Laboratory of Spatial Information and Geomatics (1207115-18). We would like to thank HePing TAO and his group at Institute of Microelectronics of Chinese Academy of Sciences for their great efforts in providing the field survey data of wind erosion.

\section{References}

Assefa M M. 2004. Spatiotemporal dynamics of land surface parameters in the Red River of the North Basin. Physics and Chemistry of the Earth, Parts A/B/C, 29: 795-810.

Bajracharya R M, Lal R, Hall G F. 1998. Temporal variation in properties of an uncropped, ploughed Miamian soil in relation to seasonal erodibility. Hydrological Process, 12: 1021-1030.

Bilbro J D, Fryrear D W. 1994. Wind erosion losses as related to plant silhouette and soil cover. Agronomy Journal, 86: 550-553.

Bruin S. 2000. Predicting the areal extent of land-cover types using classified imagery and geostatistics. Remote Sensing of Environment, 74: 387-396.

Bryan R B. 1968. The development, use and efficiency of indices of soil erodibility. Geoderma, 2: 5-26.

Buschiazzo D E, Zobeck T M. 2008. Validation of WEQ, RWEQ and WEPS wind erosion for different arable land management systems in the Argentinean Pampas. Earth Surface and Landscape Processes, 33 1839-1850.

Chappell A, Zobeck T M, Brunner G. 2006. Using bi-directional soil spectral reflectance to model soil surface changes induced by rainfall and wind-tunnel abrasion. Remote Sensing of Environment, 102: 328-343.

Chen S Q, Wang L J, Lu S H, et al. 2007. Study of NDVI and climate change in Maqu County, upstream of Yellow River. Journal of Glaciology and Geocryology, 29: 131-136. (in Chinese)

Dobrowski S Z, Pushnik J C, Zarco-Tejada P J, et al. 2005. Simple reflectance indices track heat and water stress-induced changes in steady-state chlorophyll fluorescence at the canopy scale. Remote Sensing of Environment, 97: 403-414.

Dunne J A, Saleska S R, Fischer M L, et al. 2004. Integrating experi- 
mental and gradient methods in ecological climate change research. Ecology, 85: 904-916.

Fryrear D W, Krammes C A, Williamson D L, et al. 1994. Computing the wind erodible fraction of soils. Journal of Soil and Water Conservation, 49: 183-188.

Fu X F, Yang S T, Liu C M. 2007. Changes of NDVI and their relations with principal climatic factors in the Yarlung Zangbo River Basin. Geographic Research, 26: 60-66. (in Chinese)

Geeves G W, Leys J F, McTainsh G H. 2000. Soil erodibility. In: Charman P E V, Murphy B W. Soils: Their Properties and Management. New York: Oxford University Press, 205-220.

Grini A, Zender C S. 2004. Roles of saltation, sandblasting, and wind speed variability on mineral dust aerosol size distribution during the Puerto Rican Dust Experiment (PRIDE). Journal of Geophysical Research, 109: 102-108.

Hagen L J. 1991. A wind erosion prediction system to meet users needs. Journal of Soil and Water Conservation, 46: 106-111.

Hevia G G, Mendez M, Buschiazzo D E. 2007. Tillage affects soil aggregation parameters linked with wind erosion. Geoderma, 140: $90-96$.

Huete A R, Tucker C J. 1991. Investigation of soil influences in AVHRR red and near-infrared vegetation index imagery. International Journal of Remote Sensing, 12: 1223-1242.

Ilan S, Eugene D U, Hanoch L, et al. 2008. Grazing-induced spatial variability of soil bulk density and content of moisture, organic carbon and calcium carbonate in a semi-arid rangeland. Catena, 75 : 288-296.

IPCC. 2007. Climate Change 2007: The Physical Science Basis. Contribution of Working Group I to the Fourth Assessment Report of the Intergovernmental Panel on Climate Change. Cambridge: Cambridge University Press.

Jiang D M, Liu Z M, Cao C Y, et al. 2003. Desertification and Ecological Restoration of Keerqin Sandy Land. Beijing: China Environmental Science Press, 32-142. (in Chinese)

Jiang D S, Li X H, Fan X K, et al. 1995. Discussion on soil anti-scouring properties and arrangement of soil and water conservation measure system in the contiguous areas of Shanxi, Shaanxi and Inner Mongolia. Journal of Soil and Water Conservation, 9(1): 1-7. (in Chinese)

Jing K, Wang W Z, Zheng F L. 2005. Soil Erosion and Environment in China. Beijing: Science Press. (in Chinese)

Knapp A K, Smith M D. 2001. Variation among biomes in temporal dynamics of aboveground primary production. Science, 291: 481-484.

Li F R, Zhao A F, Zhou H Y, et al. 2002. Effects of simulated grazing on grown and persistence of Artemisia frigida in a semiarid sandy rangeland. Grass and Forage Science, 57: 239-247.

Li F R, Zhang H, Zhang T H, et al. 2003. Variations of sand transportation rates in sandy grasslands along a desertification gradient in northern China. Catena, 53: 255-272.

Li F R, Zhao L Y, Zhang H, et al. 2004. Wind erosion and airborne dust deposition in farmland during spring in the Horqin Sandy Land of eastern Inner Mongolia, China. Soil and Tillage Research, 75: 121-130.
Li L H, Han X G, Wang Q B, et al. 2002. Correlations between plant biomass and soil respiration in a Leymus chinensis community in the Xilin River Basin of Inner Mongolia. Acta Botanica Sinica, 44(5): 593-597. (in Chinese)

Li X B, Chen Y H, Wang H, et al. 2004. Regional distribution of land cover change amplitude in China. Scientia Geographica Sinica, 24: 270-274. (in Chinese)

McHenry J R, Ritchie J C. 1977. Physical and chemical parameters affecting transport of CS-137 in arid watersheds. Water Resource Research, 13: 923-927.

Merrill S D, Black A L, Fryrear D W, et al. 1999. Soil wind erosion hazard of spring wheat-fallow as affected by long-term climate and tillage. Soil Science Society of America Journal, 63: 1768-1777.

Miao C Y, He B H, Chen X Y, et al. 2004. Analysis on correlativity of soil erodibility factors of USLE and WEPP models. Soil and Water Conservation in China, 6: 23-26. (in Chinese)

Mostaghimi S, Young R A, Wilts A R, et al. 1988. Effects of frost action on soil aggregate stability. Transactions of the American Society of Agricultural Engineers, 31(2): 435-439.

Mutchler C K, Carter C E. 1983. Soil erodibility variation during the year. Transactions of the American Society of Agricultural Engineers, 26: $1102-1104$.

Nakano T, Nemoto M, Shinoda M. 2008. Environmental controls on photosynthetic production and ecosystem respiration in semi-arid grasslands of Mongolia. Agricultural and Forest Meteorology, 148: 1456-1466.

Qi J, Ma W, Song C X. 2008. Influence of freeze-thaw on engineering properties of a silty soil. Cold Regions Science and Technology, 53(3): 397-404.

Rana G, Katerji N, Lorenzi F. 2005. Measurement and modelling of evapotranspiration of irrigated citrus orchard under Mediterranean conditions. Agriculture Forest Meteorology, 128(3-4): 199-209.

Raupach M R, Lu H. 2004. Representation of land-surface processes in aeolian transport models. Environmental Modelling and Software, 19: 93-112.

Shi T G, Sun X H, Yan Y C. 2003. Study on the seasonal wind-sand land in the northwest region of Shandong Province based on Remote Sensing. Areal Research and Development, 22(5): 43-45. (in Chinese)

Singh U B, Gregory J M, Wilson G R. 1999. Texas erosion analysis model: theory and validation. In: Skidmore E L, Tatarko J. Wind Erosion Proceedings of an International Symposium/Workshop, 3-5 June 1997. Kansas State University, Manhattan: United States Department of Agriculture (USDA), Agricultural Research Service, Wind Erosion Research Unit.

Stow D A, Hope A, MacGuire D, et al. 2004. Remote sensing of vegetation and land-cover change in Arctic Tundra Ecosystems. Remote Sensing of Environment, 89: 281-308.

Sutherland R A, Kowalchuk T, Dejong E. 1991. Cesium-137 estimates of sediment redistribution by wind. Soil Science, 151(15): 387-396.

Thorne M E, Young F I, Pan W I, et al. 2003. No-till spring cereal cropping systems reduce wind erosion susceptibility in the wheat-fallow region of the Pacific Northwest. Journal of Soil and Water Conservation, 58(5): 251-257. 
Vaezi A R, Sadeghi S R H, Bahrami H A, et al. 2008. Modeling the USLE K-factor for calcareous soils in northwestern Iran. Geomorphology, 97: 414-423.

Verheijen F G A, Jones R J A, Rickson R J, et al. 2009. Tolerable versus actual soil erosion rates in Europe. Earth-Science Reviews, 94: 23-38.

Webb N P, McGowan H A, Phinn S R, et al. 2009. A model to predict land susceptibility to wind erosion in western Queensland, Australia. Environmental Modelling and Software, 24: 214-227.

Wei Z G, Huang R H, Chen W, et al. 2002. Spatial distributions and interdecadal variations of the snow at the Tibetan Plateau weather stations. Chinese Journal of Atmospheric Sciences, 26(4): 496-508. (in Chinese)

Wood K, Rubio H, Wood C. 2008. Rangeland management and hydrology. In: Proceedings XXI International Grassland Congress and VII International Rangeland Congress. Hohhot, China, 809-812.

Zhang C L, Gong J R, Zou X Y, et al. 2003. Estimates of soil movement in a study area in Gonghe Basin, north-east of Qinghai-Tibet Plateau. Journal of Arid Environments, 53(3): 283-285.
Zhang H B, Luo Y M, Zhao Q G, et al. 2006. Hong Kong soil researches VI. integrated evaluation of soil fertility quality based on the improved analytic hierarchy process. Acta Pedologica Sinica, 43(4): 577-583. (in Chinese)

Zhang J G, Liu S Z, Yang S Q. 2007. The classification and assessment of freeze-thaw erosion in Tibet. Journal of Geographical Sciences, 2: $165-174$.

Zhang W J, Gao Z Q. 2006. Spatial variation of water/thermal elements and NDVI with altitudes in central and eastern Tibetan Plateau. Geographic Research, 25: 877-886. (in Chinese)

Zhao X G, Shi H. 2003. Prescription of soil anti-erosion capabilty under water erosion. Arid Land Geography, 26(1): 12-16. (in Chinese)

Zhou P H, Wu C L. 1993. The research method of soil anti-scouribility experiment on the Loess Plateau. Journal of Soil and Water Conservation, 7(1): 29-34. (in Chinese)

Zhou Z C, Shangguan Z P. 2006. Soil anti-scourability during the vegetation succession in Ziwuling secondary forest. Acta Ecologica Sinica, 26(10): 3270-3275. (in Chinese)

Zhu Z, Chen G T. 1994. The Sandy Desertification in China. Beijing: Science Press, 250-268. (in Chinese) 